REVIEW

\title{
Should office workers spend fewer hours at their computer? A systematic review of the literature
}

\author{
S IJmker, M A Huysmans, B M Blatter, A J van der Beek, W van Mechelen, P M Bongers
}

Occup Environ Med 2007;64:211-222. doi: 10.1136/oem.2006.026468

Worldwide, millions of office workers use a computer. Reports of adverse health effects due to computer use have received considerable media attention. This systematic review summarises the evidence for a relationship between the duration of work time spent using the computer and the incidence of hand-arm and neck-shoulder symptoms and disorders. Several databases were systematically searched up to 6 November 2005. Two reviewers independently selected articles that presented a risk estimate for the duration of computer use, included an outcome measure related to handarm or neck-shoulder symptoms or disorders, and had a longitudinal study design. The strength of the evidence was based on methodological quality and consistency of the results. Nine relevant articles were identified, of which six were rated as high quality. Moderate evidence was concluded for a positive association between the duration of mouse use and hand-arm symptoms. For this association, indications for a dose-response relationship were found. Risk estimates were in general stronger for the hand-arm region than for the neck-shoulder region, and stronger for mouse use than for total computer use and keyboard use. A pathophysiological model focusing on the overuse of muscles during computer use supports these differences. Future studies are needed to improve our understanding of safe levels of computer use by measuring the duration of computer use in a more objective way, differentiating between total computer use, mouse use and keyboard use, attaining sufficient exposure contrast, and collecting data on disability caused by symptoms.

See end of article for authors' affiliations

Correspondence to: S IJmker, Body@Work TNO VUmc, Institute for Research in Extramural Medicine (EMGO), Van der Boechorststraat 7, 1081 BT Amsterdam, The

Netherlands; s.ijmker@ vumc.nl

Accepted 20 October 2006 Published Online First 9 November 2006
$T$ he large-scale introduction of computers in the workplace has led to hundreds of millions of computer users worldwide. ${ }^{12}$ In many countries, the widespread use of computers has led to considerable media attention concerning potential adverse health effects.

In the scientific literature, the rise and fall of an epidemic of "repetitive strain injuries" (ie, workers reporting and claiming compensation for disorders of hand, arm, shoulder or neck) in Australia during the 1980s has been fuelling the debate of whether computer use at work is a potential occupational hazard. ${ }^{3}$ Proponents stated that repetitive movements and static load due to constrained working postures caused the "injuries". Critics focused on the absence of objective clinical signs among patients and the role of a liberal compensation system, offering large sums of money to workers who were unable to work because of hand, arm, shoulder or neck symptoms. ${ }^{4}$ Some authors argued that lost lawsuits of workers against their employers were main contributing factors to the decline of the epidemic. ${ }^{5}$ In 1988, Bammer and Martin ${ }^{4}$ concluded that the debate was characterised by a lack of empirical evidence to support many of the assertions made by both the proponents and the critics of the workrelatedness of repetitive strain injuries.

In this review, we focus on the empirical evidence available for an association between the duration of work time spent using the computer (referred to as "duration of computer use") and hand, arm, shoulder or neck symptoms and disorders. Previous reviews suggest that an association between the duration of computer use and disorders of hand, arm, shoulder or neck is present. In addition, computer use might be more strongly related to disorders of the hand and arm, than to disorders of the neck and shoulders. ${ }^{6-9}$ However, the limitation of these reviews is that they are mainly based on cross-sectional studies. ${ }^{6-8}$ Cross-sectional studies cannot disentangle causes and effects, and are therefore considered to be inferior to longitudinal studies. ${ }^{10}$ The recent narrative review by Wahlström ${ }^{9}$ includes only part of the available longitudinal studies.

To get a more conclusive insight into the relationship between the duration of computer use and the incidence of hand-arm and neckshoulder symptoms and disorders, a systematic review of longitudinal studies was performed. Since information on potential dose-response relationships is lacking, specific attention will be paid to this issue.

\section{METHODS}

\section{Search strategy}

Publications were retrieved by a computerised search of the following databases: Medline (from 1950 to November 2005), NIOSHTIC 2, CISDOC, HSELINE, MHIDAS, OSHLINE (all from 1985 to April 2005) and PsycINFO (from 1967 to April 2005). The databases were searched for published articles up to 6 November 2005. The keywords included: retrospective, prospective, longitudinal, follow-up, computer, keyboard, mouse, office, display, VDU, VDT, terminal, neck, shoulder, elbow, wrist, hand, upper extremity, upper limb, musculoskeletal, pain, physical symptom and

Abbreviations: NUDATA, Neck and Upper extremity Disorders Among Technical Assistants 
physical health. After inclusion of the articles based on the selection criteria, references were checked for additional articles. Finally, personal databases of the authors were searched for relevant articles.

\section{Selection criteria}

Two reviewers (SIJ and MAH) independently selected relevant articles from the articles retrieved with the search strategy. The articles were selected based on the abstracts. If abstracts provided insufficient information, the full text of the articles was used. The selection criteria were: (1) the study population included computer workers; (2) the outcome included one or more syndromes, signs or symptoms related to pain or discomfort in hand, arm, shoulder or neck; (3) a risk estimate of the association between the duration of computer use, mouse use or keyboard use and a relevant outcome measure (see 2) was presented; (4) the study had a longitudinal design (ie, at least one follow-up measurement after baseline); and (5) the study was a full-text, peer-reviewed article, written in English, Dutch or German. Experimental studies, letters and abstracts were excluded.

\section{Quality assessment}

The articles that met the selection criteria were evaluated for methodological quality. We used a quality assessment list for prospective cohort studies, based on previous systematic reviews of risk factors for musculoskeletal disorders. ${ }^{11-14}$ Box 1 presents the full list of items.

Two reviewers (SIJ and MAH) independently assessed the quality of the studies. All items were scored positive, negative or unclear (ie, meaning that insufficient information was available). For each item, the scoring of the two reviewers was compared. In case of disagreement, consensus was reached during a meeting. If agreement could not be reached, a third reviewer $(\mathrm{AJvdB})$ decided the matter. Subsequently, the first author of the included articles was contacted to provide an opportunity to discuss the quality assessment of their articles. Methodological quality assessment was based on the percentage of positive items over the total number of items. A highquality study was defined as scoring positive on $>50 \%$ of the items, which is in concordance with previously published systematic reviews. ${ }^{11-14}$

\section{Data extraction}

Details on study population, exposure assessment, outcome assessment and data analysis were extracted from all articles. To examine the agreement between the two reviewers for the selection of articles and for the methodological quality assessment, Cohen's $\kappa$ coefficients were calculated.

To evaluate the associations between the duration of computer use and hand, arm, shoulder and neck disorders, we decided to stratify according to the measure of computer use that was reported (total computer use, mouse use or keyboard use) and according to the location of the symptoms or disorders (ie, neck-shoulder or hand-arm). Elbow symptoms were classified as hand-arm symptoms.

An association was scored positive if the risk estimate (odds ratio (OR), rate ratio (RR) or hazard ratio (HR)) was statistically significant, or if at least one of the presented exposure categories showed a point estimate $>2$ (or $<0.5)$.

\section{Levels of evidence}

To summarise the results of the studies, we used levels of evidence. Strong evidence was defined as consistent results for all tested associations, including at least two high-quality studies. We anticipated that one article could present multiple associations for different case definitions and that multiple articles could present associations for the same cohort of
Box 1 Quality assessment list for prospective cohort studies

- Study design

- Was the participation rate at baseline at least $80 \%$ odds ratio (OR), if participation rate was $<80 \%$, not selective regarding exposure (ie, duration of computer use) and potential confounders (ie, at least for sex and age)?

- Was the response at follow-up at least $80 \%$ OR, if the response was $<80 \%$, not selective regarding exposure (ie, duration of computer use), potential effect modifiers (ie, at least sex and age) and outcome (ie, hand, arm, shoulder and neck symptoms, or disorders)?

- Exposure assessment

- Were the data on duration of computer use collected using standardised methods of acceptable quality?*

- Were the data on ergonomic factors collected using standardised methods of acceptable quality?*

- Were the data on psychosocial factors collected using standardised methods of acceptable quality? $†$

- Were the data on physical factors during leisure time collected and used in the analysis?

- Were the data on exposure change regarding the duration of computer use during the follow-up period (eg, due to job change) collected and used in the analysis?

- Outcome assessment

- Were the data on outcome collected using standardised methods of acceptable quality?

- Data analysis

- Was the statistical method used appropriate for the outcome studied and was a measure of association presented, including $95 \% \mathrm{Cl}$ or $\mathrm{p}$ value?

- Was the statistical analysis tested for confounding by sex and age?

- Was the number of subjects in the multivariate analysis at least 10 times the number of independent variables?

${ }^{*}$ ICC $>0.6$ or $\kappa>0.4$ for test-retest reliability or interobserver reliability. Additionally, for self-reports: ICC $>0.6$ or $\kappa>0.4$ or $r>0.75$ for agreement with observation or direct measurement.

†ICC $>0.6$ or $\kappa>0.4$ for test-retest reliability. Additionally for self-reports, in the case of using scales: Cronbach's $\alpha>0.7$ for the majority of scales used.

fICC $>0.6$ or $\kappa>0.4$ or $r>0.75$ for test-retest reliability or interobserver reliability, or if (modified) Nordic questionnaire was used. ${ }^{15-17}$

workers. Therefore, multiple positive associations from the same cohort of workers were counted as one study.

The criterion of consistent results was met if at least $75 \%$ of all tested associations for the risk factor were positive (ie, provided a statistically significant risk estimate, or a risk estimate $>2$ or $<0.5$ ). 
Moderate evidence was defined as consistent results for all tested associations (with a minimum of three associations tested) or consistent results for at least two high-quality studies, irrespective of the findings from medium-quality studies for that association. Insufficient evidence was defined as inconsistent results for all tested associations, including the situation in which less than three associations were evaluated.

\section{Dose-response analysis}

The dose-response relationship was evaluated if at least moderate evidence was available for an increased risk of developing hand-arm or neck-shoulder symptoms or disorders. We assessed dose-response qualitatively by plotting the point estimates against the exposure categories. Therefore, we extracted the point estimates for all reported exposure categories. We used the middle value of the lower and upper limit to reflect the average duration of computer use for that exposure category. If there was no upper limit for the highest exposure category, we conservatively used the lower limits to reflect the duration of computer use. Some studies presented exposure categories as a percentage of working time. On the basis of the distribution of working hours at baseline, we estimated the average number of working hours for the whole population and multiplied this average with the percentage of computer use to calculate the average duration of computer use for each exposure category. A general increase of risk (ie, higher point estimates) over increasing duration categories for most studies was considered as evidence for a dose-response relationship.

\section{RESULTS}

\section{Search results}

The search strategy resulted in 277 hits. Applying the selection criteria resulted in nine articles. We excluded the longitudinal study by Lindström et al, ${ }^{18}$ because cross-sectional analyses were performed. The two reviewers initially disagreed on the selection of one article, resulting in a $\kappa$ of 0.94 . The references of the included articles provided another article. ${ }^{19}$ The final set of articles was based on five cohorts of workers: (1) the Behavior in Information Technology Study ${ }^{20}{ }^{21}$; (2) the Neck and Upper extremity Disorders Among Technical Assistants (NUDATA) Study ${ }^{22-25}$; (3) Bergqvist et al ${ }^{19}$; (4) Marcus et al ${ }^{26}$; and (5) Korhonen et al. ${ }^{27}$ Table 1 gives the characteristics and results of the included articles.

\section{Methodological quality assessment}

Table 2 presents the methodological quality assessment of the articles. The $\kappa$ coefficient for the agreement between the ratings of the individual items (positive vs negative or unclear) of the two reviewers was 0.91 (disagreement on 5 of 108 scored items). One item needed a decision of the third reviewer $(\mathrm{AJvdB})$; agreement on the other items was reached during the consensus meeting. Eight of nine corresponding authors replied to our invitation to discuss the quality assessment. On the basis of the information, five unclear scores were replaced by positive scores. Six studies had a quality score exceeding $50 \%$, which we considered as the cut-off point for high quality. ${ }^{22-27}$

\section{Levels of evidence}

Figures 1 and 2 present point estimates and 95\% CIs, derived from the original articles, for the associations between the duration of total computer use, mouse use and keyboard use and hand-arm and neck-shoulder symptoms and disorders, respectively. We excluded one of the associations studied by Bergqvist et al, ${ }^{19}$ because the case definition involved anatomical locations from both the hand-arm and the neck-shoulder region. Risk estimates were in general larger for mouse use than for total computer use and keyboard use. For neck-shoulder symptoms and disorders, fewer associations were positive than for hand-arm symptoms and disorders.

For hand-arm symptoms and disorders, moderate evidence was concluded for the association with duration of mouse use, because all studies showed a positive association, including three high quality studies based on the NUDATA cohort. ${ }^{22} 2325$ However, these were counted as one study. For the duration of total computer use and the duration of keyboard use, insufficient evidence was concluded, because inconsistent results were found. For the duration of total computer use, associations from three cohorts were available. Only the NUDATA cohort investigated the duration of keyboard use.

For neck-shoulder symptoms and disorders, insufficient evidence was concluded for the duration of mouse use and the duration of keyboard use, since inconsistent results were found. For both mouse use and keyboard use, only the NUDATA cohort investigated the association with neckshoulder symptoms and disorders. For the duration of total computer use, all tested associations failed to show a positive association. Four cohorts investigated total computer use, including two high-quality studies. ${ }^{26} 27$

\section{Dose-response analysis}

Following the criteria set beforehand, we analysed the relationship between the duration of mouse use and the incidence of hand-arm symptoms. In general, an increase in risk over duration categories can be observed from fig 3. However, the association between mouse use and hand-wrist symptoms reported by Jensen ${ }^{20}$ and the association between mouse use and "severe" hand-wrist pain found by Lassen et al ${ }^{25}$ did not show a clear increasing risk over duration categories (fig 3 ). Jensen $^{20}$ reported an increased risk (OR 4) at a rather short duration of mouse use (ie, approximately $4.5 \mathrm{~h}$ per week), as well as an increased risk (OR 4) at a long duration of mouse use (ie, approximately $27 \mathrm{~h}$ per week). Lassen $e t$ al ${ }^{25}$ presented a drop in risk from 4.8 to 2.3 for their highest exposure category (ie, $>30 \mathrm{~h}$ per week).

\section{DISCUSSION}

The results of this review of longitudinal studies confirm the finding of previous reviews. The duration of computer use was more consistently associated with hand-arm than with neckshoulder symptoms and disorders. ${ }^{6} 9$ In addition, our review adds to the existing literature the observation that the duration of mouse use was more strongly and more consistently associated with the incidence of hand-arm symptoms than the duration of total computer use and keyboard use.

\section{Methodological considerations}

All the studies included in this review have substantial methodological quality, since they were based on longitudinal study designs, and all but one scored positive on the quality items with regard to statistical analysis. Still, the design of future studies might be improved by taking into account a number of methodological limitations that are present in the published studies.

First, all studies used self-report measurements to assess the duration of computer use. No study reported data on the testretest reliability of these self-reports. Low test-retest reliability might be related to a poor validity of exposure measures. Moreover, several studies have shown that self-report measurements, on average, strongly overestimate the duration of computer use, resulting in misclassification..$^{28}{ }^{29}$ Assuming that this misclassification is non-differential, this would lead to an underestimation of the true exposure-response relationship. ${ }^{30} \mathrm{~A}$ recent development is the use of computer software to objectively measure the duration of computer use. Such 


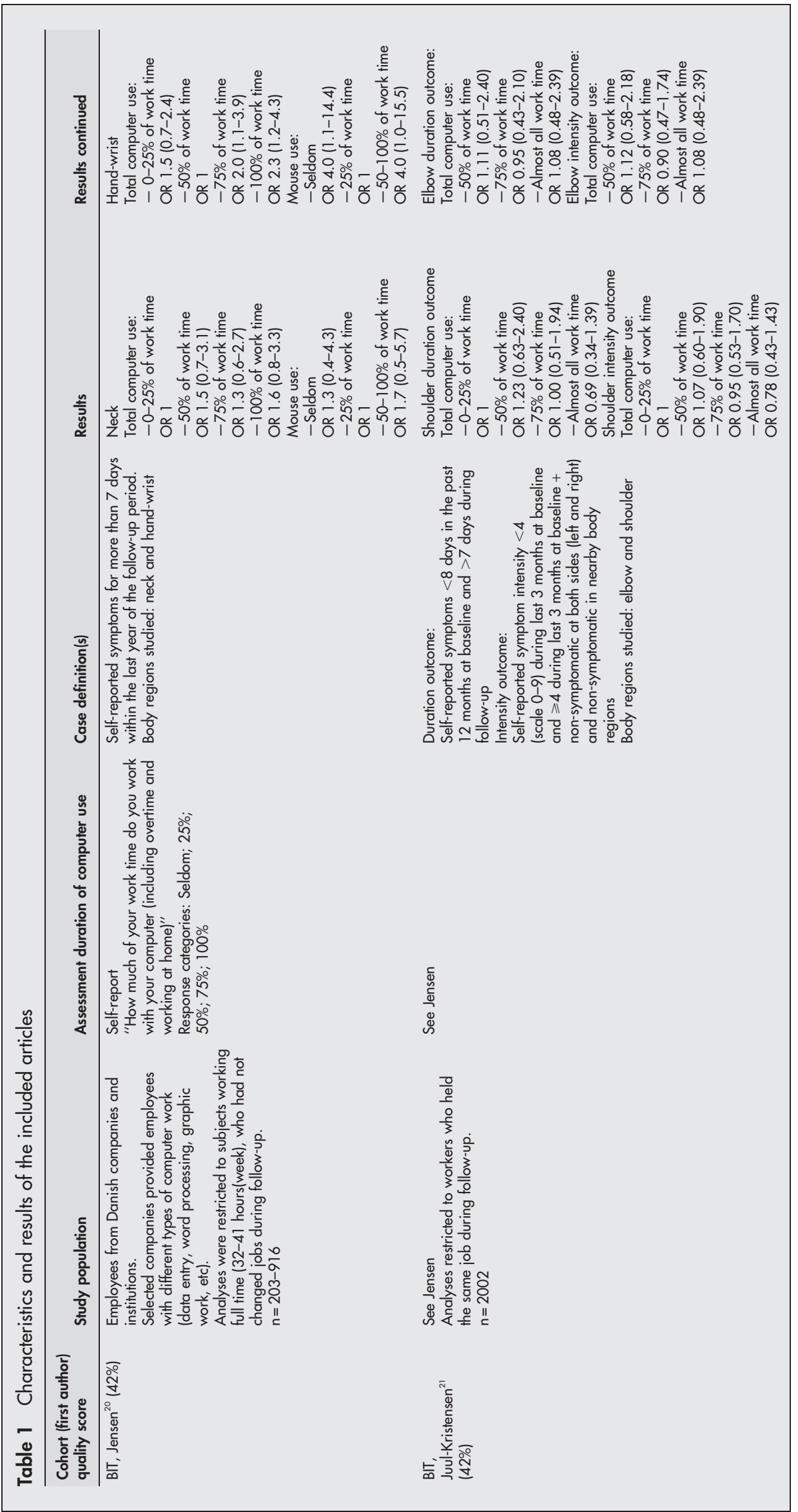




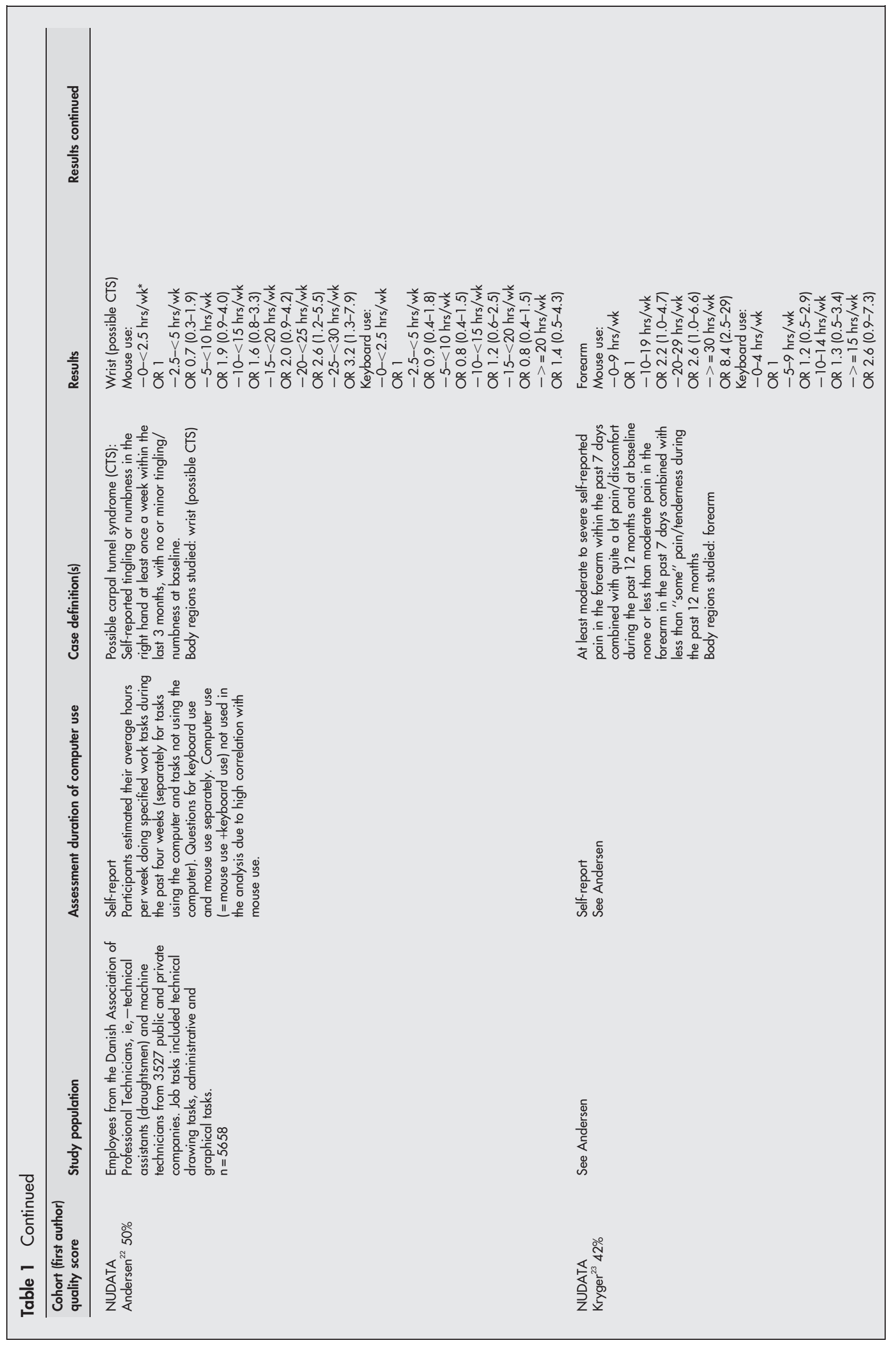




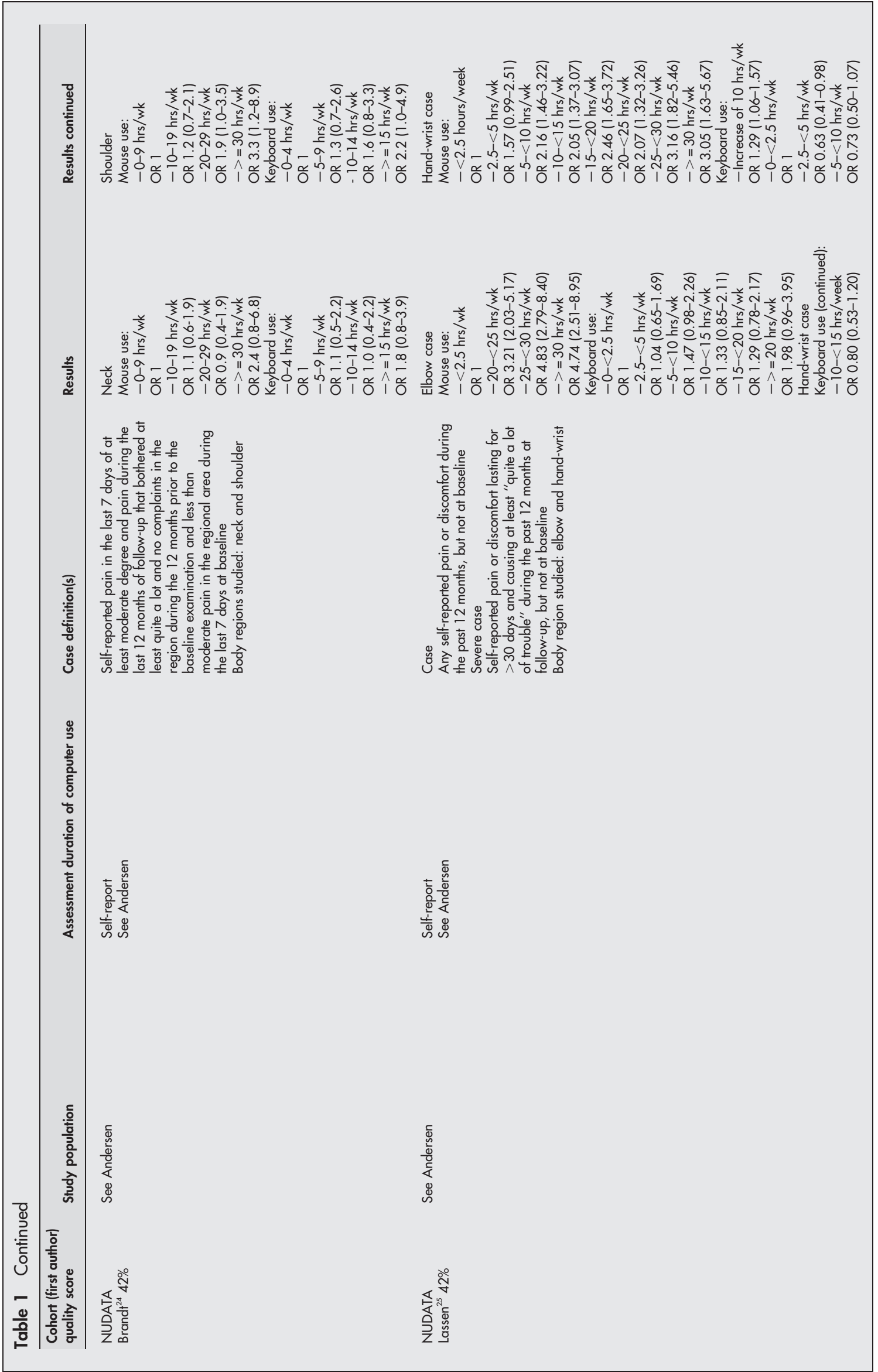




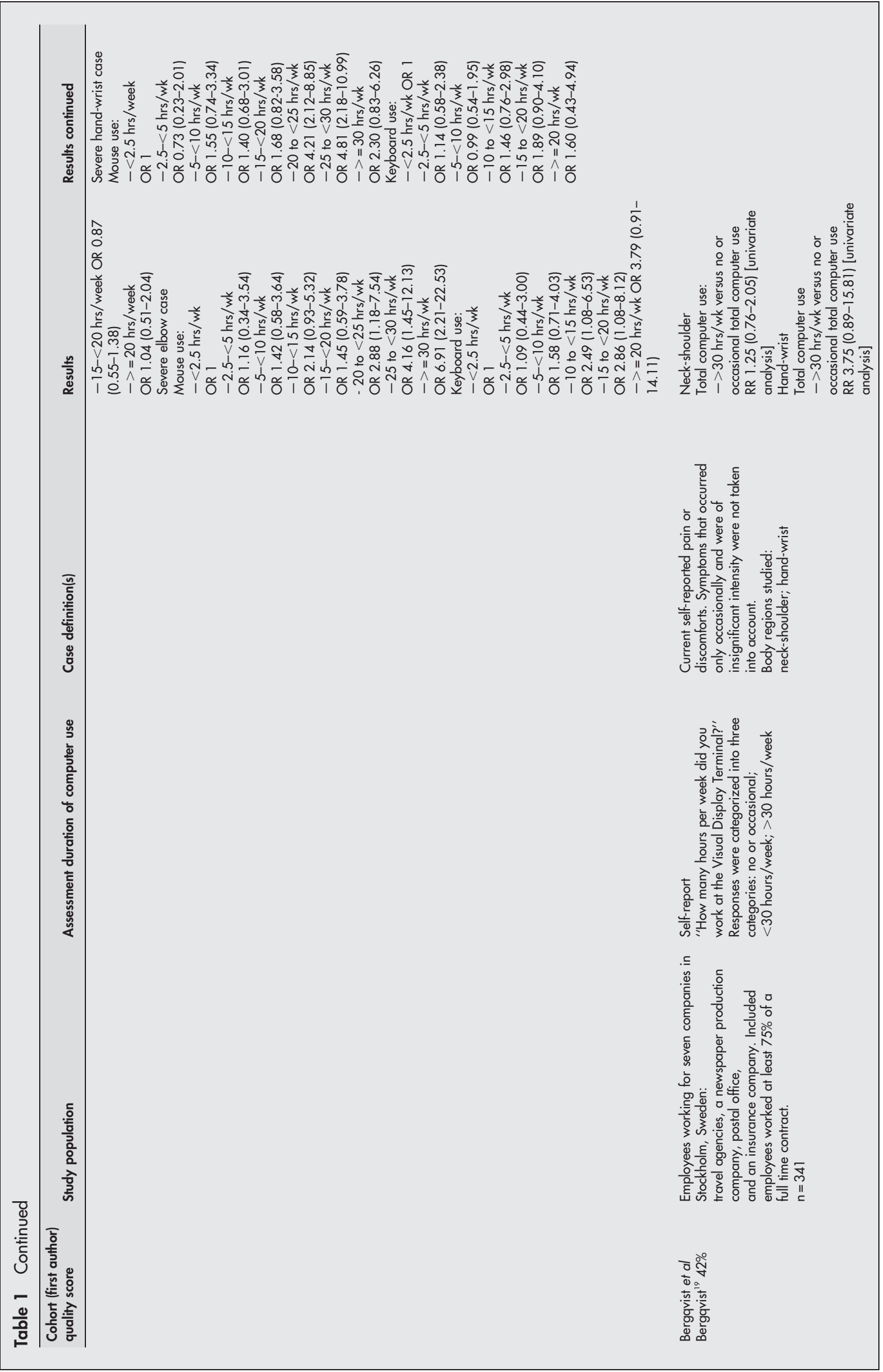




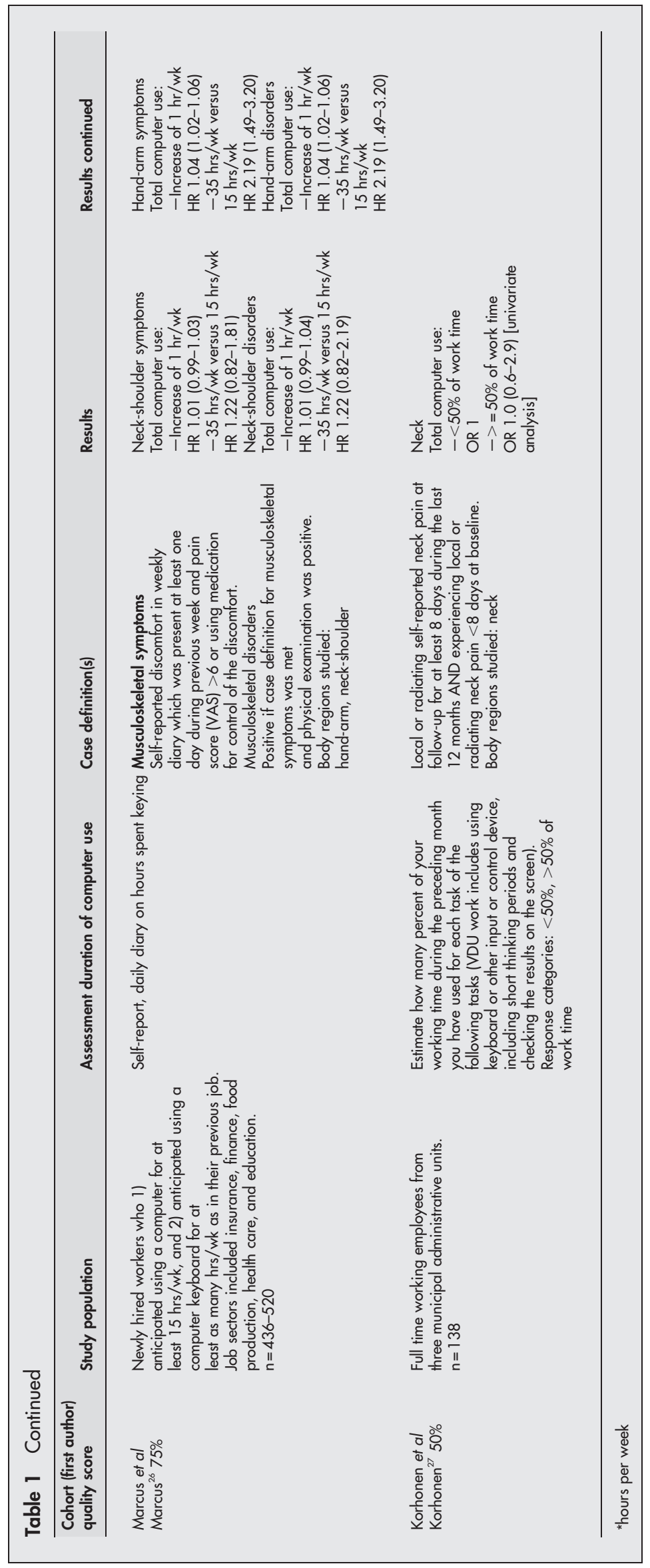




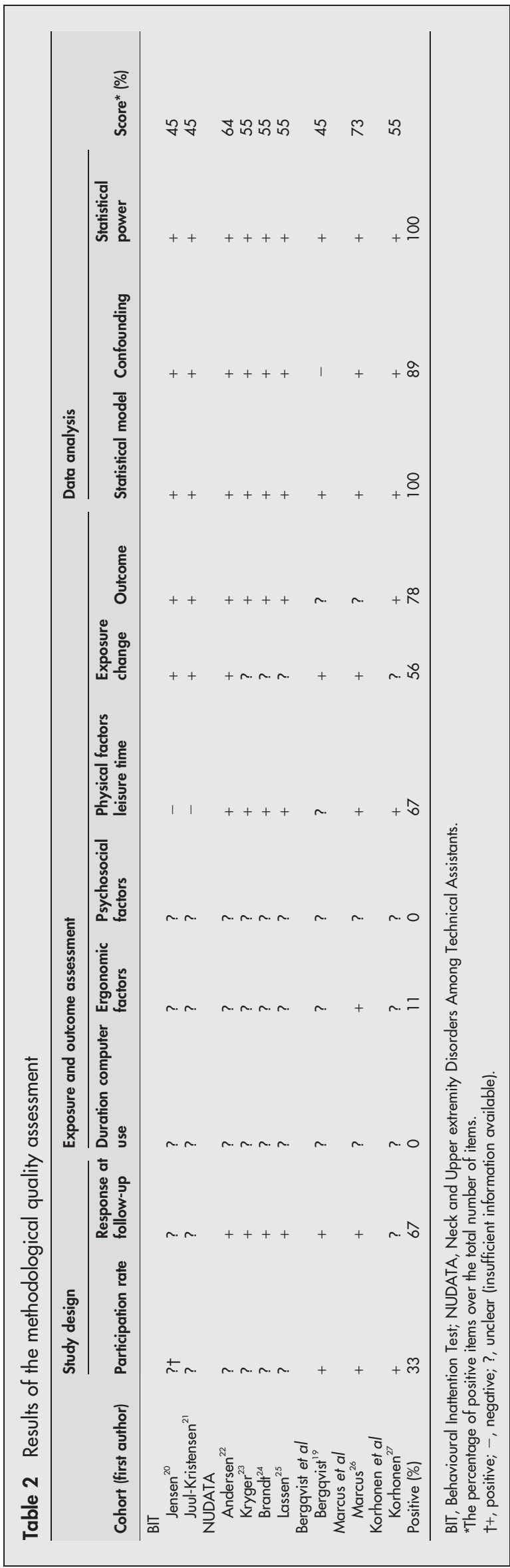

software showed good agreement with observation, ${ }^{31}$ and has already been used in an epidemiological study. ${ }^{29}$

Second, most studies in this review solely measured the duration of total computer use. General measures of the duration of computer use might not be able to detect the variability in the duration of mouse and keyboard use. This might explain the stronger risk estimates for the duration of mouse use in comparison with those for the duration of total computer use. However, within the NUDATA cohort total computer use was not analysed, since it was highly related to mouse use. ${ }^{22}$

Third, all included articles had study populations consisting solely of computer users. This might have led to a limited exposure contrast (ie, only the contrast present within the group of computer users) and a limited power to explain the contributing factors to the incidence of hand, arm, shoulder and neck symptoms among computer users. ${ }^{6}$

Fourth, most case definitions were based on arbitrary cut-off points, based on the number of days on which pain or discomfort was experienced. In the NUDATA Study,,$^{24}{ }^{25}$ few participants met the criteria for a clinical diagnosis during follow-up (ie, $<2 \%$ incidence for both neck-shoulder and hand-arm disorders). In addition, self-reports showed mild disability. In contrast with the NUDATA Study, the study by Marcus et $a l^{26}$ (see Gerr et $a l^{32}$ ) showed a high incidence of clinical diagnoses (ie, 35\% incidence of neck-shoulder disorders and $21 \%$ incidence of hand-wrist disorders). One of the explanations for this difference between studies might be that the population studied by Marcus et al consisted of newly hired workers. Newly hired workers might be more prone to health problems, because they are not experienced with the physical and psychosocial exposures that they have to deal with in the new job. The difference might also be attributed to selection effects within the NUDATA cohort: workers who are susceptible to or have had hand, arm, shoulder or neck symptoms and disorders might have migrated to jobs with lower durations of exposure or might have left the workforce. Kryger et $a l^{23}$ indicated that the criteria used to establish a clinical diagnosis might be different between the NUDATA study and the one reported by Marcus et $a^{26}$ ( see Gerr $e^{2} a^{32}$ ). In addition, it should be noted that physical examination might not have sufficient interobserver reliability ${ }^{33}$ and that information on validity is largely unknown. ${ }^{34}$

On the basis of the limitations of physical examinations on the one hand, and the identical risk estimates for self-reported symptoms and clinically diagnosed disorders in the study by Marcus $e t a^{26}$ on the other hand, self-reports of the degree of disability caused by symptoms might be preferred to grade the severity of symptoms in future epidemiological studies.

To estimate safe levels of the duration of computer use more precisely, more high-quality studies are needed. These studies should focus on measuring the duration of computer use in a more objective way, differentiating between total computer use, mouse use and keyboard use, attaining sufficient exposure contrast, and collecting data on disability caused by symptoms.

\section{Sensitivity analysis}

The levels of evidence proposed in this review might have been influenced by arbitrary decisions regarding the criteria used in the methodological quality assessment. The methodological quality score ranged between $45 \%$ and $73 \%$, with seven of nine studies scoring between $45 \%$ and $55 \%$. On the basis of this distribution, our a priori cut-off point of $>50 \%$ might have influenced the levels of evidence and potentially the results of this review. Shifting the cut-off point from $>50 \%$ to $>40 \%$, would have only changed the level of evidence for the combination of mouse use and hand-arm symptoms and disorders. Strong evidence, instead of moderate evidence, 


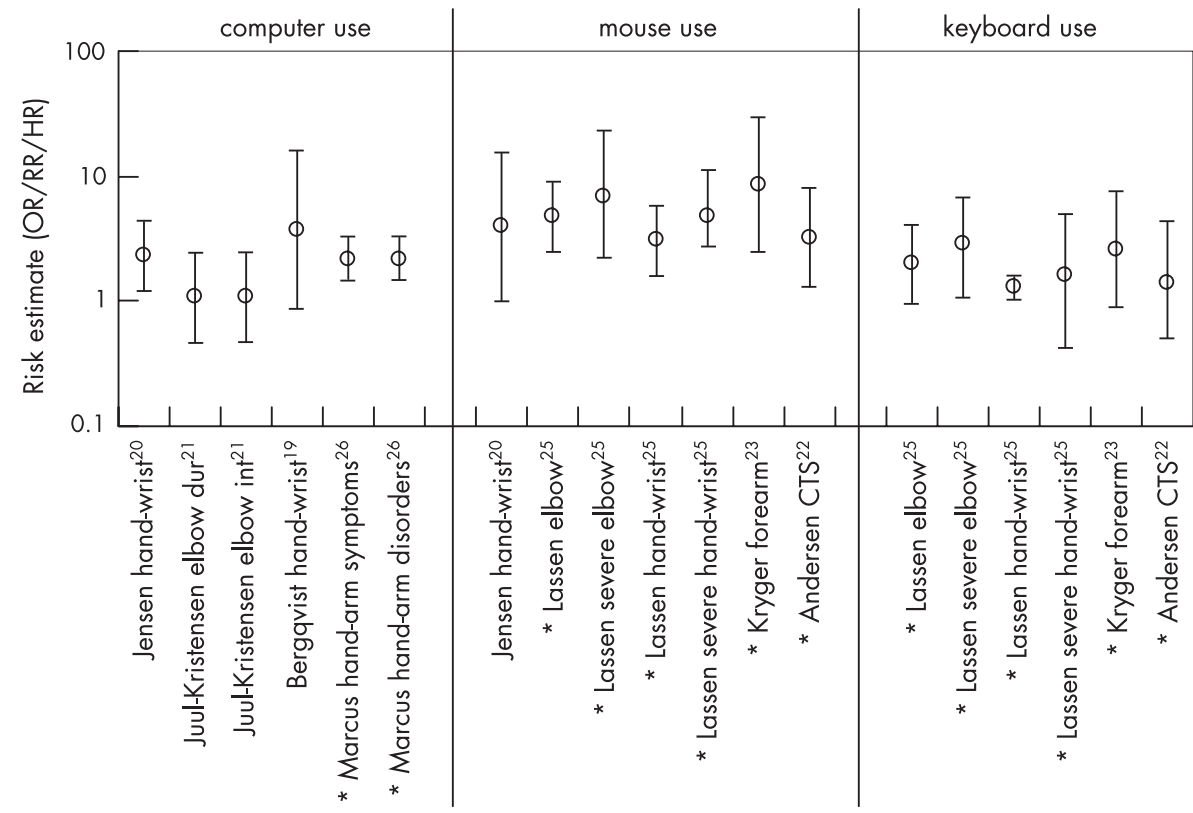

Figure 1 Risk estimates for the association between duration of computer use and hand-arm symptoms and disorders. See the italic numbers in the results columns of table 1 for exact values (*, high-quality study). CTS, carpal tunnel syndrome; $\mathrm{HR}$, hazard ratio; $O R$, odds ratio; $R R$, rate ratio.

would have been concluded. By contrast, shifting the cut-off point to $>60 \%$ would not have influenced our levels of evidence at all.

Variation of exposure contrasts between studies might also have influenced the levels of evidence via the consistency of results. Studies analysing limited exposure contrasts are less likely to find a positive association than studies analysing large exposure contrasts. Large variations in exposure contrast between studies were only available for the associations between the duration of total computer use and both handarm and neck-shoulder symptoms and disorders. However, variation in exposure contrast was not likely to influence the levels of evidence for these associations. For the association between the duration of mouse use and neck-shoulder symptoms, a higher exposure contrast in the study by Jensen $^{20}$ might have led to a positive association. In that case, moderate evidence instead of insufficient evidence would have been concluded.

\section{Dose-response analysis}

In general, the dose-response analysis for hand-arm symptoms showed an increase in point estimates over an increasing duration of mouse use. Jensen $e a^{20}$ presented an increased risk at a rather low duration of mouse use and again at a high duration of mouse use. It is possible that residual confounding was present in their study, because subjects who had a low

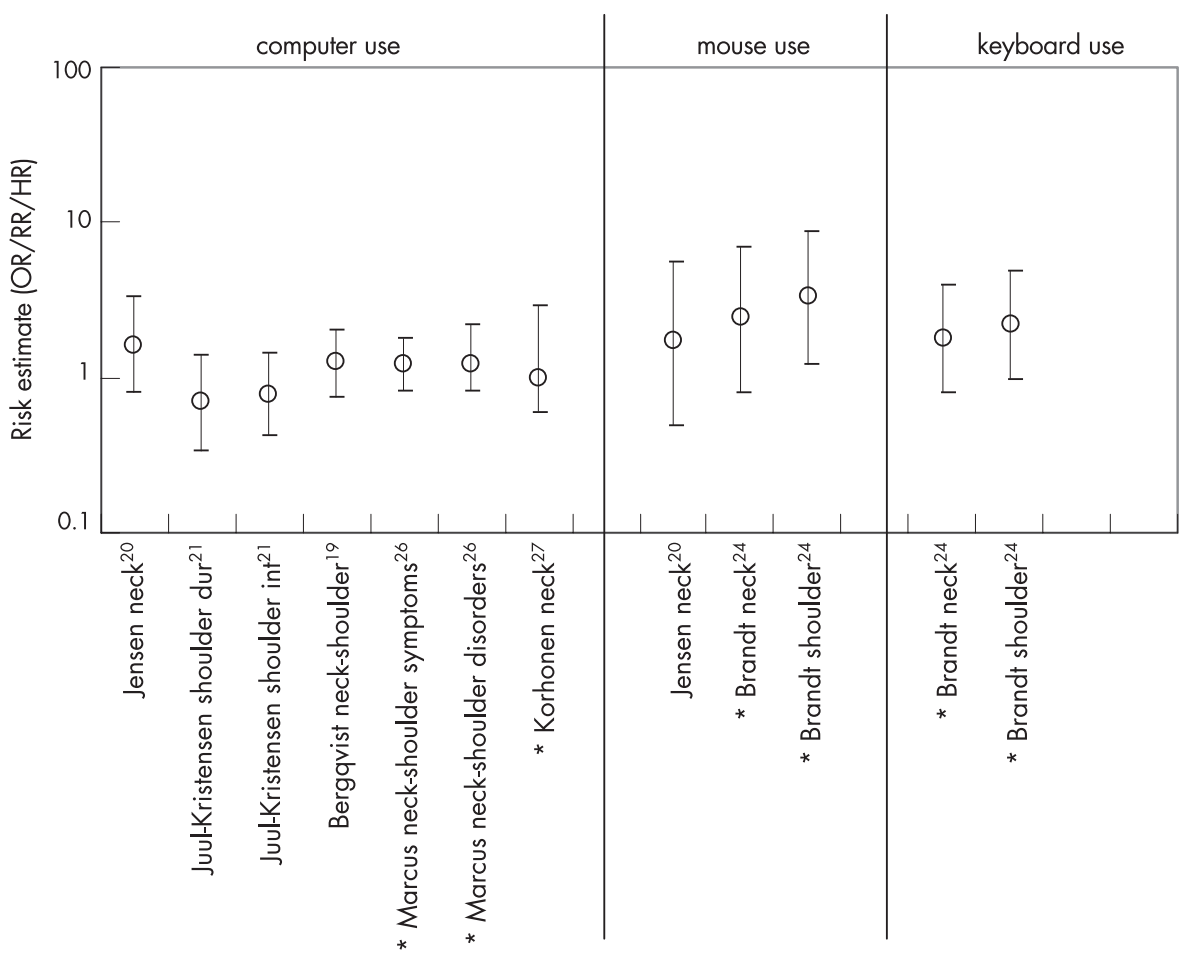

Figure 2 Risk estimates for the association between duration of computer use and neckshoulder symptoms and disorders. See the italic numbers in the results columns of table 1 for exact values (*, high-quality study). HR, hazard ratio; OR, odds ratio; $R R$, rate ratio. 


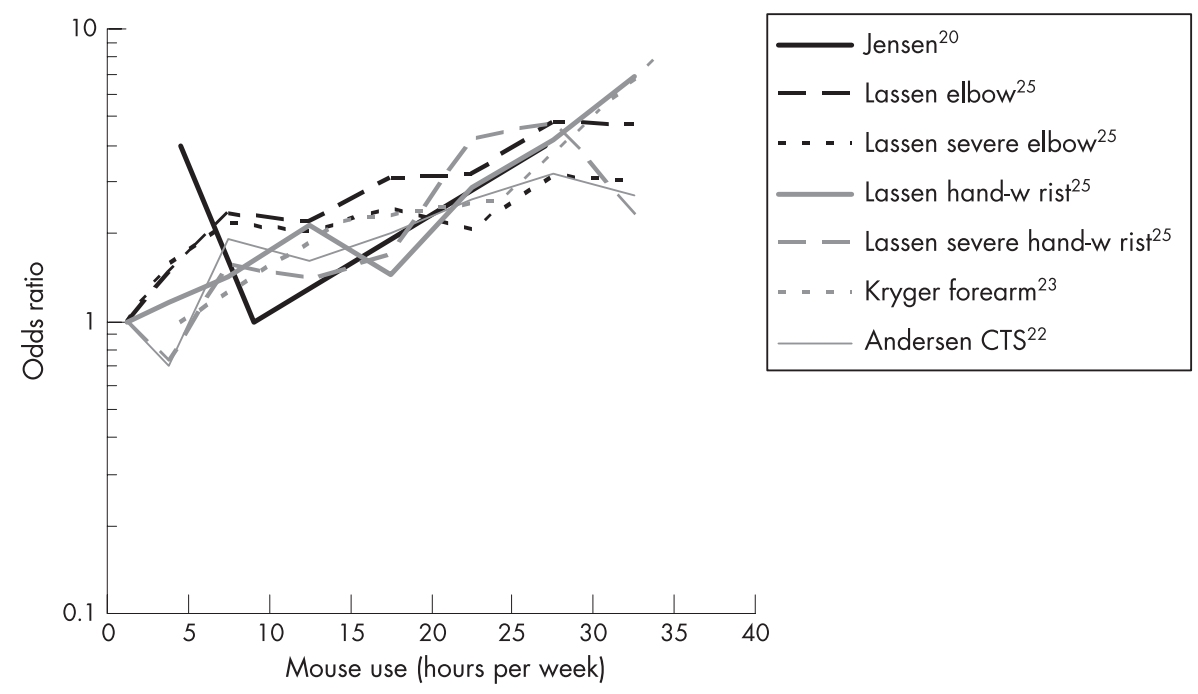

Figure 3 Odds ratios for the association between the duration of mouse use and hand-arm symptoms.

\section{Main messages}

- Longitudinal studies provide moderate evidence for an association between the duration of mouse use and the incidence of hand-arm symptoms among office workers.

- Future studies are needed to improve our understanding of safe levels of occupational computer use by dealing with the methodological limitations of the studies published so far.

exposure to mouse use might have had a high exposure to keyboard use, leading to a long duration of total computer use and thus an increased risk.

Lassen et $a^{25}$ showed a decreased risk for developing severe hand-wrist pain at their highest exposure category (ie, $>30 \mathrm{~h}$ per week). A possible explanation is a saturation of biological pathways, or the presence of less susceptible workers at the highest exposure category due to selection in the past. ${ }^{35}$

To be able to explore a dose-response relationship, we assumed that the relationship between the point estimates of increasing exposure categories was linear. In addition, we had to estimate the average exposure within an exposure category. Both these factors might have biased our findings. However, these assumptions did not influence our general conclusion that the risk of developing hand-arm symptoms is higher at longer self-reported durations of mouse use.

\section{Biological plausibility}

The studies in this review that investigated the effects of the same exposure contrast on both the hand-arm and the neckshoulder region, generally showed stronger risk estimates for the hand-arm region than for the neck-shoulder region. Studies on muscle activity during computer use are in line with these findings, since they indicate a higher loading of the hand-arm region (extensors of the wrist) than of the neckshoulder region (trapezius muscle). ${ }^{36-38}$ In addition, Laursen et $a l^{39}$ found fewer electromyographic gaps in the extensor muscles of the wrist than in the trapezius muscle during computer use, potentially indicating longer periods of continuous activation of local muscle fibres belonging to the same motor unit. The findings from both lines of research are supported by a hypothesis that attributes a central role to the overuse of muscles and the physiological consequences of this overuse in the pathophysiological mechanism underlying hand, arm, shoulder and neck symptoms and disorders. ${ }^{40}$

Stronger risk estimates were found for mouse use than for keyboard use and total computer use. This difference can also be interpreted using the muscle overuse mechanism described above. Less variation in working postures during mouse use has been observed in comparison with keyboard work, ${ }^{36}{ }^{41}$ potentially leading to a longer duration of continuous muscle loading. ${ }^{42}$

On the basis of the above, it seems that evidence for a pathophysiological mechanism is available. However, caution is advised. The central role of muscles in the pathophysiological mechanism has been criticised..$^{43}$ In addition, it should be borne in mind that the evidence found in this review for and against associations was based on a limited number of studies. In addition, data for the effects of mouse and keyboard use are for the larger part derived from the NUDATA cohort. The possibility that a long duration of keyboard use can be a risk factor for developing hand, arm, shoulder or neck symptoms and disorders cannot be excluded, since only a limited range of exposures to keyboard use was available in the NUDATA cohort.

\section{Limitations of this review}

The conclusions of this review are based on a rather low number of cohort studies. Therefore, it is possible that the conclusions might change when new studies become available in the future.

A second limitation is that we compared studies with different case definitions. This might have influenced the results. Future research might indicate whether the associations between the duration of computer use and hand-arm or neck-shoulder symptoms are sensitive to these differences in case definition.

In addition, our review focused on only one contributing factor to the incidence of hand-arm and neck-shoulder symptoms and disorders among computer users (ie, duration of computer use). This does not represent the general concept of a multifactorial origin of musculoskeletal disorders. ${ }^{69}$ Moreover, it might be possible that other factors related to computer use (such as working postures or mental demands) act as effect modifiers of the association between the duration of computer use and hand-arm and neck-shoulder symptoms. A combination of, for example, high mental demands and long duration of computer use might lead to a higher incidence than a long duration of computer use in itself. This might explain the 
observed variation between study populations of the effect of a longer daily duration of computer use.

\section{CONCLUSION}

This review showed moderate evidence for an association between the duration of mouse use and the incidence of handarm symptoms. Indications for a dose-response were found. In addition, the neck-shoulder region seemed less susceptible to exposure to computer use than the hand-arm region. Both findings are supported by a pathophysiological mechanism based on the overuse of muscles during computer use. The low number of high-quality studies prevents drawing a firm conclusion. More research is needed to confirm our findings.

\section{ACKNOWLEDGEMENTS}

We thank Jaap van Dieën for helpful comments on an earlier version of the manuscript.

\section{Authors' affiliations}

S IJmker, A J van der Beek, W van Mechelen, Department of Public and Occupational Health, Institute for Research in Extramural Medicine (EMGO), VU University Medical Centre, Amsterdam, The Netherlands B M Blatter, P M Bongers, TNO Quality of Life, Hoofddorp, The Netherlands

M A Huysmans, Institute for Fundamental and Clinical Human Movement Sciences (IFKB), Faculty of Human Movement Sciences, Vrije Universiteit, Amsterdam, The Netherlands

Funding: This article was prepared as part of a PhD project within the framework of the Body@Work TNO VUmc Research Centre. This study was supported by the VU University Medical Centre and TNO Quality of Life Fund Body@Work TNO VUmc. No external funding was obtained for this article.

Competing interests: None.

\section{REFERENCES}

Freeman RB. The labour market in the new information economy. Oxford Rev Econ Policy 2002; 18:288-305.

2 Andries F, Smulders PGW, Dhondt S. The use of computers among the workers in the European Union and its impact on the quality of work. Behav Inf Technol 2002:21:441-7.

3 Hall W, Morrow L. 'Repetition strain injury': an Australian epidemic of upper limb pain. Soc Sci Med 1988;27:645-9.

4 Bammer G, Martin B. The arguments about RSI: an examination. Community Health Stud 1988;12:348-58.

5 Szabo RM, King KJ. Repetitive stress injury: diagnosis or self-fulfilling prophecy? [Review]. J Bone Joint Surg Am 2000;82:1314-22.

6 Punnett L, Bergqvist U. Visual display unit work and upper extremity nusculoskeletal disorders: a review of epidemiological findings [review]. Arbete och Hälsa 1997; 16:1-161.

7 Tittiranonda P, Burastero S, Rempel D. Risk factors for musculoskeletal disorders among computer users [review]. Occup Med 1999;14:17-38.

8 Gerr F, Marcus M, Monteilh C. Epidemiology of musculoskeletal disorders among computer users: lesson learned from the role of posture and keyboard use [review]. J Electromyogr Kinesiol 2004;14:25-31.

9 Wahlström J. Ergonomics, musculoskeletal disorders and computer work review]. Occup Med 2005:55:168-76.

10 Rothman KJ, Greenland S. Causation and causal inference. Causation and causal inference. In: Rothman KJ, Greenland S, eds. Modern epidemiology, 5th edn. Philadelphia, PA: Lippincott-Raven, 1998:7-28.

11 Hoogendoorn WE, van Poppel MN, Bongers PM, et al. Physical load during work and leisure time as risk factors for back pain [review]. Scand J Work Environ Health 1999:25:387-403.

12 Ariens GA, van Mechelen W, Bongers PM, et al. Physical risk factors for neck pain [review]. Scand J Work Environ Health 2000;26:7-19.

13 Van der Windt DA, Thomas E, Pope DP, et al. Occupational risk factors for shoulder pain: a systematic review [review]. Occup Environ Med 2000:57:433-42.

14 Hooftman WE, van Poppel MN, van der Beek AJ, et al. Gender differences in the relations between work-related physical and psychosocial risk factors and musculoskeletal complaints [review]. Scand J Work Environ Health 2004;30:261-78

15 Kuorinka I, Jonsson B, Kilbom A, et al. Standardised Nordic questionnaires for the analysis of musculoskeletal symptoms. Appl Ergon 1987:18:233-7.

16 Baron S, Hales T, Hurrell J. Evaluation of symptom surveys for occupational musculoskeletal disorders. Am J Ind Med 1996;29:609-17.

17 Palmer K, Smith G, Kellingray S, et al. Repeatability and validity of an upper limb and neck discomfort questionnaire: the utility of the standardized Nordic questionnaire. Occup Med (Lond) 1999;49:171-5.

18 Lindström K, Leino T, Seitsamo J, et al. A longitudinal study of work characteristics and health complaints among insurance employees in VDT Work. Int J Hum Comput Interact 1997;9:343-68.

19 Bergqvist U, Knave B, Voss M, et al. A longitudinal study of VDT work and health. Int J Hum Comput Interact 1992;4:197-219.

20 Jensen C. Development of neck and hand-wrist symptoms in relation to duration of computer use at work. Scand J Work Environ Health 2003:29:197-205.

21 Juul Kristensen B, Sogaard K, Stroyer J, et al. Computer users' risk factors for developing shoulder, elbow and back symptoms. Scand J Work Environ Health 2004;30:390-8

22 Andersen JH, Thomsen JF, Overgaard E, et al. Computer use and carpal tunne syndrome. A 1-year follow-up study. JAMA 2003;289:2963-9.

23 Kryger Al, Andersen JH, Lassen CF, et al. Does computer use pose an occupational hazard for forearm pain; from the NUDATA Study. Occup Environ Med 2003;60:el4.

24 Brandt LP, Andersen JH, Lassen CF, et al. Neck and shoulder symptoms and disorders among Danish computer workers. Scand J Work Environ Health 2004;30:399-409.

25 Lassen CF, Mikkelsen S, Kryger Al, et al. Elbow and wrist/hand symptoms among 6,943 computer operators: a 1-year follow-up study (the NUDATA Study). Am J Ind Med 2004:46:521-33.

26 Marcus M, Gerr F, Monteilh C, et al. A prospective study on computer users: II. Postural risk factors for musculoskeletal symptoms and disorders. Am J Ind Med 2002;41:236-49.

27 Korhonen T, Ketola R, Toivonen R, et al. Work related and individual predictors for incident neck pain among office employees working with video display units. Occup Environ Med 2003;60:475-82.

28 Heinrich J, Blatter BM, Bongers PM. A comparison of methods for the assessment of postural load and duration of computer use. Occup Environ Med 2004:61:1027-31.

29 Lassen CF, Mikkelsen S, Kryger Al, et al. Risk factors for persistent elbow, forearm and hand pain among computer workers. Scand J Work Environ Health 2005;31:122-31.

30 Armstrong BG. Effect of measurement error on epidemiological studies of environmental and occupational exposures [review]. Occup Environ Med 1998;55:651-6.

31 Blangsted AK, Hansen K, Jensen C. Validation of a commercial software package for quantification of computer use. Int J Ind Ergon 2004:34:237-41.

32 Gerr F, Marcus M, Ensor C, et al. A prospective study of computer users: I. Study design and incidence of musculoskeletal symptoms and disorders. Am J Ind Med 2002;41:221-35.

33 Salerno DF, Franzblau A, Werner RA et al. Reliability of physical examination of the upper extremity among keyboard operators. Am J Ind Med 2000;37:423-30.

34 Marx RG, Bombardier C, Wright JG. What do we know about the reliability and validity of physical examination tests used to examine the upper extremity? [Review]. J Hand Surg [Am] 1999;24:185-93.

35 Steenland K, Deddens JA. A practical guide to dose-response analyses and risk assessment in occupational epidemiology [review]. Epidemiology 2004; 15:63-70.

36 Bystrom JU, Hansson GA, Rylander L, et al. Physical workload on neck and upper limb using two CAD applications. Appl Ergon 2002;33:63-74.

37 Jensen C, Borg V, Finsen L, et al. Job demands, muscle activity and musculoskeletal symptoms in relation to work with the computer mouse. Scand J Work Environ Health 1998;24:418-24.

38 Fernstrom $\mathbf{E}$, Ericson MO. Computer mouse or Trackpoint-effects on muscular load and operator experience. Appl Ergon 1997;28:347-54.

39 Laursen B, Jensen BR, Garde AH, et al. Effect of mental and physical demands on muscular activity during the use of a computer mouse and a keyboard. Scand J Work Environ Health 2002;28:215-21.

40 Visser B, van Dieën JH. Pathophysiology of upper extremity muscle disorders. J Electromyogr Kinesiol 2006;16:1-16.

41 Karlqvist L, Hagberg M, Selin K. Variation in upper limb posture and movement during word processing with and without mouse use. Ergonomics 1994:37:1261-7

42 Jensen C, Finsen L, Hansen K, et al. Upper trapezius muscle activity patterns during repetitive manual material handling and work with a computer mouse. J Electromyogr Kinesiol 1999:9:317-25.

43 Knardahl S. Psychophysiological mechanisms of pain in computer work: the blood vessel-nociceptor interaction hypothesis. Work Stress 2002; 16:179-89. 